\title{
10. Skill flows and the Fourth Industrial Revolution: future questions and directions for the ASEAN Economic Community
}

\section{Anna Fink and Elisabetta Gentile*}

\section{INTRODUCTION}

In 1969, the independent calculations and communications required to guide the National Aeronautics and Space Administration's (NASA's) Apollo 11 mission were performed by mainframe computers that cost \$3.5 million each and were the size of a car. Today, even the simplest Wi-Fi router is more powerful, much smaller, and at the same time much, much cheaper than the technology that put the first man on the moon. Although this process of technological upgrading spanned over 50 years, a major shift occurred at the turn of the 21 st century, with the convergence of a wide range of breakthroughs - not just digital (e.g., artificial intelligence), but also physical (e.g., new materials) and biological (e.g., bio-engineering). Economist Klaus Schwab, who coined the term "Fourth Industrial Revolution (4IR)" to refer to this ongoing process, says the accelerating pace of change, breadth, and depth of these technologies is "fundamentally changing the way we live, work, and relate to one another" (Schwab 2016).

The emergence of these disruptive technologies, especially in the digital sphere, could be a boon for the ASEAN Economic Community (AEC). According to the Master Plan on ASEAN Connectivity 2025, digital technologies - particularly mobile internet, big data, cloud technology, the internet of things, the automation of knowledge work, and the SocialMobile-Analytics-Cloud (SMAC) - could potentially unleash up to $\$ 625$ billion by 2030 ( $8 \%$ of ASEAN's projected gross domestic product [GDP]) through increased efficiency, new products and services, and digital public goods (ASEAN 2016). The Master Plan goes on to identify education, e-commerce, payments solutions, and cloud-based technologies as areas 
where ASEAN could be at the forefront of change, as opposed to simply utilizing existing technologies.

However, new technologies also present new challenges. ASEAN members are already experiencing shortages of skilled labor, and current trends indicate that by 2025 more than half the high-skilled jobs in Cambodia, Indonesia, the Lao People's Democratic Republic, the Philippines, Thailand, and Viet Nam-some 25.6 million jobs - could be filled by workers without sufficient qualifications (ILO and ADB 2014). Therefore, disruption to the labor market is one of the major challenges the AEC will have to tackle regionally (WEF and ADB 2017).

As discussed in Chapter 2, skill flows can help alleviate skill gaps by creating better matches between employers and employees and enabling the transfer of know-how across borders. It is no surprise, then, that the Master Plan reaffirms ASEAN's commitment to facilitate the mobility of skilled labor and university students.

Combined with ASEAN's continuing demographic transition and structural transformation, the 4IR is also changing the way we think about skilled workers. The AEC concluded regional arrangements for the mutual recognition of professional qualifications in tourism and six regulated occupations: accounting, architecture, dentistry, engineering, medicine, and nursing (ADB 2017b). Most of these professions require higher education and/or on-the-job training. However, technical-vocational profiles must also play an important role in the 4IR, as they possess the practical, hands-on skills aligned with the demands of the labor market. The commitment in the Master Plan to strengthen skills mobility "by establishing high-quality qualification framework in critical vocational occupations" (ASEAN 2016) is an encouraging first step toward thinking of skilled workers as those whose profiles are in high demand, rather than workers who are above a certain "skill threshold." The Global Commission on International Migration suggests using the term "essential workers" instead of defining workers as high- or low-skilled (GCIM 2005).

It is still a matter of debate how the technologies of the 4IR will affect skill flows. Some predict that ease of access to information will result in increased mobility of skilled workers; others claim that digital technologies will usher in the era of "virtual migration" (Aneesh 2006), in which work crosses national boundaries through online capital, labor, and information flows.

In this chapter, we seek to add to ongoing debates on how the 4IR will affect ASEAN in the context of skill flows and labor mobility. We do this by reviewing some of the literature on the impact of the 4IR on skilled employment, and then focus on its implications for skill flows-both digital and physical — within the region. We go on to consider how 4IR 
technologies can support and further our understanding of physical skilled labor mobility. We conclude with a summary of some of the areas for further research and policy issues for ASEAN to consider.

Although the role of skills mobility in this new economy will likely vary by occupation, we believe that it remains of strategic importance to support growth and inclusiveness in the region. Furthermore, skilled workers increasingly "have mentalities and connections that are much more global in nature than those of their predecessors" (Baldwin 2016), which means that if ASEAN fails to create an environment conducive to skill flows, skilled workers will simply go elsewhere.

\section{THE FOURTH INDUSTRIAL REVOLUTION AND SKILLED EMPLOYMENT}

Attempts to quantify the impact of 4IR technologies on employment build on the labor economics literature on the task content of employment (Autor et al. 2003; Autor and Dorn 2013). Instead of categorizing jobs as high-, middle- or low-skilled based on factors like occupation or level of educational achievement, this literature looks at the task content of a specific occupation. An occupation is routine if it involves tasks performed regularly and easily standardized, and nonroutine if it requires problemsolving and complex communications. Routine and nonroutine occupations can be further categorized as cognitive or manual. As mentioned in Section 1, the relationship of routine and nonroutine with high-, middle-, and low-skilled work is complicated (and shifting). But, largely, nonroutine cognitive tasks (carried out by researchers, teachers, and managers) are considered high-skilled, whereas routine manual work (cashiers and assembly line workers) are considered low-skilled.

Frey and Osborne (2017) link data from the O*NET database, which contains survey-based information on the task content of each occupation with 2010 employment and wage data from the United States (US) Bureau of Labor Statistics (BLS) to predict the probability of automating 70 occupations. They find that $47 \%$ of total US-based employment is at high risk of automation, with office and administrative support, sales, and other mostly middle-skilled service occupations taking the biggest hit.

Using the methodology from Frey and Osborne (2017), Chang and Huynh (2016) study the impact of technologies on employment in Cambodia, Indonesia, the Philippines, Thailand, and Viet Nam, and conclude that up to $56 \%$ of all employment in these countries is at risk of displacement due to technology over the next decade or two. Occupations at high risk are largely routine tasks that can increasingly 
be automated-for example, as carried out by sewing machine operators, shop and sales persons, food service personnel, and office clerks. Industry experts also estimated that $47 \%$ of business process outsourcing (BPO) workers in the Philippines are focused on process-driven tasks that will be challenged by increasingly sophisticated voice and text/image recognition (AfDB et al. 2018). The characteristics of essential workers in the 4IR will therefore be determined less by level of training, knowledge, and the expertise required to do the job, and more about whether humans hold a comparative advantage over machines in doing the work. Based on current and expected technological advancements, this will mean workers with skills in communications, problem solving, empathy, moral values, and complicated manual dexterity will have the advantage.

The methodology in Frey and Osborne (2017) and Chang and Huynh (2016) - which we call an "occupation-based approach" - has several shortcomings. First, automation does not target entire occupations, but specific tasks within an occupation. Second, the automation of one or more tasks in an occupation may be technically but not economically feasible. For example, while it may technically be possible to automate the production of clothes, sewbots remain expensive compared to the average apparel and footwear wages in Asia (ADB 2018). ${ }^{1}$ Third, even if it is both technically and economically feasible to automate one or more tasks, workers can adapt to the new division of labor by switching tasks. Furthermore, 4IR technologies, as with past technologies, could be complementary to workers, enabling them to increase productivity, leading to higher wages within sectors and productivity spillovers to other industries. This can support general economic and employment growth. Finally, by using Frey and Osborne's data on the probability of automation in the US, Chang and Huynh assume that the task contents for each occupation are similar across countries. These shortcomings suggest the occupation-based approach by Frey and Osborne may seriously overestimate the risk of automation for entire occupations.

Arntz et al. (2016) take a "task-based approach" to estimate the susceptibility of employment to automation for 21 Organisation for Economic Co-operation and Development (OECD) countries. They use individual survey data from the Programme for the International Assessment of Adult Competencies (PIAAC), which provides a list of tasks people actually perform at their workplace. They find that only $9 \%$ of jobs in the US are at high risk of automation, compared with the $47 \%$ estimated by Frey and Osborne.

This task-based approach has some of the same faults as the occupationbased approach: it is still based on technical feasibility rather than actual adoption of new technologies, and it does not consider whether workers 
adapt to the new division of labor. Furthermore, it only analyzes existing occupations when new technologies tend to create new jobs (Stewart et al. 2015). Nonetheless, these are limitations that would be difficult to overcome by any study.

Unfortunately, the task-based approach in Arntz et al. cannot be replicated for ASEAN countries because detailed survey-based data with task content of occupations are unavailable for developing Asia. However, compared to Chang and Huynh, we can hypothesize that it would yield a lower number of jobs at high risk of automation. Thus, fears of the jobs lost from 4IR technologies in the Asia and Pacific region may be overstated. Task-based approaches show that the technical automation of jobs may be lower than feared under occupation-based approaches - and these estimates do not consider economic feasibility and potential productivity gains.

An additional reason why the impact of 4IR technologies in developing Asia may not be as severe is that the region continues to undergo structural transformation - a movement of employment from agriculture to industry and services. Developing Asia has created 30 million non-agricultural jobs annually over the past 25 years (ADB 2018), partly due to structural transformation as well as technology-driven improvements in productivity.

Another key driver of employment in the region has been participation in global value chains (GVCs). In 2016, Asia's GVC participation was 61.1\% (ADB 2017a), second only to the European Union (EU). Factories located across Asian economies form a regional production network in which parts and components are produced and then assembled into a final product, which is then shipped largely to advanced economies. ${ }^{2}$ This high level of integration means that technology adoption and location of production are not independent decisions, and therefore technological advances along the supply chain can result in the elimination or relocation of jobs. ${ }^{3}$

GVCs were born out of unbundling production processes across national borders (Baldwin 2016). The "first unbundling" was prompted by falling transportation costs and marked the end of the necessity to make goods in the same place as the consumer; falling communication and coordination costs led to a "second unbundling," which ended the need for manufacturing stages to be performed near one another. Right now, a "third unbundling" is underway in which individual jobs, processes, and services are being optimized with the aid of digital technology. The latest unbundling is affecting every sector of the economy, including the professions - previously considered impervious to automation by virtue of their hard-earned expertise. Indeed, the fragmentation of expertise into a series of streamlined processes is already underway. Some of these processes will still require traditional professional input, but others 
are being standardized and performed by technology or outsourced to individuals who do not need to be locally licensed (Susskind and Susskind 2015).

A forecasting exercise to predict how 4IR technologies will affect the structure of GVCs in developing Asia - and therefore employmentwould require heavy assumptions, with the results quite sensitive to those assumptions. The next best thing is to focus on a recent period during which a great deal of technological upgrading occurred across the region and infer potential future trends.

Bertulfo et al. (2019) combine multiregional input-output tables with employment data from labor force surveys to examine the relationship between technology and jobs along supply chains in 12 economies in developing Asia, ${ }^{4}$ covering 35 sectors from 2005 to 2015. They decompose the overall change in employment during the decade - an 11\% increaseinto technology, task relocation (i.e., offshoring), consumer demand, and consumer preferences. They find that, holding all other factors constant, technology improvements within GVCs would have been associated with a $46 \%$ decrease in employment for the 12 countries during 2005-2015. At the same time, increased demand for goods and services from within the domestic economy would have resulted in an $80 \%$ increase in employment, holding all other factors constant. As the outlook for ASEAN economic growth is robust, the share of middle- and upper-income classes projected to rise from $48.3 \%$ in 2010 to $78.6 \%$ in 2030 , and the value of the consumer market to expand by a factor of four-from $\$ 1,098$ billion to $\$ 4,425$ billion (Kobayashi et al. 2017) — we can confidently state that, in the near future, and even in the face of technological change, the rise of this new middle class and its demand for goods and services will generate increased employment.

Nevertheless, even as overall employment grows, the distribution of that employment will shift and be hard to predict. Bertulfo et al. go on to look at the change in the share of nonroutine cognitive, nonroutine manual, routine cognitive, and routine manual occupations (i.e., employment composition) associated with improved technology within a GVC. In manufacturing, the share of nonroutine cognitive occupations unequivocally increases, whereas the share of all other categories decreases. Because the services sectors in the 12 developing Asian countries have different compositions, the results for services paint a mixed picture. For example, the Philippines, Thailand, and Viet Nam see an increase in the share of nonroutine manual occupations, whereas Indonesia sees an increase in the share of nonroutine cognitive and routine manual occupations. Overall, the analysis in Bertulfo et al. suggests that even if the increase in labor demand associated with rising demand for goods and services 
in the domestic market more than offsets the decrease in labor demand associated with technology, the quality and distribution of jobs should be of greater interest than the total number of jobs, as the impact of job loss on individual livelihoods will still be significant. Due to the rapid growth in developing economies, inequality between countries in the region is falling. But at the same time inequality within countries is rising, as jobs are created in urban areas with high concentrations of skilled workers, with other areas experiencing job loss or displacement (McKenzie 2017).

National inequality can impact long-term growth by undermining social cohesion. In the case of skill flows, anxiety over inequalities can set public attitudes against immigration. The International Labour Organization Four-Country Study on Public Attitudes to Migrant Workers (ILO 2011) surveyed people in Malaysia, Singapore, the Republic of Korea, and Thailand. It found that $88 \%$ of respondents in Singapore, $79 \%$ in the Republic of Korea, $76 \%$ in Malaysia, and 55\% in Thailand agreed there is a need for migrant workers to fill certain labor market niches. ${ }^{5}$ Yet, at the same time, about $80 \%$ of respondents in Malaysia, Singapore, and Thailand felt that government policies to admit migrant workers should be more restrictive. And it is not always the case that skilled workers are more welcome than low-skilled workers (Tunon and Baruah 2012). During the 2011 general election in Singapore, "foreign talent" - professionals with well-paying jobs - was a hot-button issue. An interesting finding for the three ASEAN members in the study is that respondents were less likely to agree with reducing the number of skilled workers from other ASEAN countries (17\% in Singapore, $18 \%$ in Thailand, and 29\% in Malaysia).

Another aspect of the third unbundling is growing ability to work remotely, either through digital technologies (e-mail, videoconference) or more advanced technological developments such as telepresence and telerobotics, which allow workers to physically perform tasks in a place other than their true location. This is the "spatial unfixing of work" (Graham et al. 2017), giving rise to the "gig economy" and the "human cloud." Online platforms have increased the ability of employers to outsource tasks to independent workers ("microwork" and "elancing"), with major implications for skill flows, as we discuss next.

\section{IMPLICATIONS FOR SKILL FLOWS}

It is undeniable that the digitization of information through 4IR technology is playing a major role in the global growth of skilled migration. ${ }^{6}$ It allows both workers and employers to overcome information asymmetries associated with cross-country job searches. Therefore, "competition for 
high-income jobs has become global and the caliber of competitors has never been higher" (McKenzie 2017). In this global labor market, skilled workers are willing to move from country to country for opportunities to advance their skills, or simply to use them more effectively, a phenomenon known as "transit migration." For example, nearly 14\% of those with tertiary education who migrated to the US during 2001-2012 lived in a country other than their birthplace prior to their arrival (Artuc and Ozden 2018). High-income OECD countries are particularly important transit stops for immigrants due to their proximity to more attractive labor markets possibly less accessible via direct migration.

Another pattern has emerged over recent decades - facilitated by the modern transport and communication that keep families and communities connected (even over great geographical distances). It is one of increasingly temporary and circular-skilled migration. ${ }^{7}$ The OECD estimates that in 2016, roughly 4.2 million workers migrated to or around OECD countries on temporary migration programs - an $11 \%$ increase from 2015-as opposed to fewer than 500,000 permanent migrants (OECD 2018). Through circular migration, migrants get "the best of both worlds" - the purchasing power of their high-income country wages is even higher in their lower-income countries of origin.

Although temporary migration per se is not a new phenomenon, it has become a salient feature of the 4IR because the third unbundling requires a growing supply of workers who not only possess specialized skills, but are also flexible enough to respond to the needs of a fast-changing labor market. Employers increasingly value diversity, especially those with a markedly international profile - such as multinational corporations, financial institutions, and multilateral organizations. For these employers, rotation in overseas postings is often a prerequisite for career advancement. What was once the prerogative of a few technical, seasonal, creative, or scientific professions has become a pervasive reality that clashes with the myth "that many erstwhile temporary and circular migrants intend to - and eventually do-become permanent settlers at the destination" (Hugo 2013).

Bijwaard and Wahba (2014) use an extremely comprehensive dataset to study the effect of a migrant's earnings on the duration of their migration experience. Their unique administrative data from the Netherlands contains detailed monthly information on all immigrants from developing countries who have entered the country between 1999 and 2007, allowing them to construct a full labor market and migration history. Their model explicitly accounts for the fact that income is endogenous - that individuals who are more talented, educated, experienced, and bold, among others, tend to earn higher wages - and for economic conditions in the country 
of origin. They find that return intensities are U-shaped with respect to income, which means that low- and high-income groups are more likely to return, with the likelihood being the highest for low-income migrants. This is consistent with successful high-income migrants leaving once they have reached their savings or human capital accumulation targets, and low-income migrants returning for failing to do so.

Of interest is the fact that, "while high-skilled workers are more likely to re-migrate as a group, those at the very highest skill levels are less likely to do so" (Kerr et al. 2016). Data from the Survey of Earned Doctorates shows that in 2005-2015, the fraction of US doctorate recipients with temporary visas from the top 10 countries of origin who intended to stay in the US was high (except for Thailand at 28\%). Approximately 9 out of 10 US doctorate recipients from Iran, India, and the People's Republic of China (PRC) intended to stay in the US, and the remaining top countries had "stay rates" ranging from $50 \%$ to $65 \%$ (NSF 2017). The incidence of return migration for foreign research scientists in the US is small, especially in STEM fields, and decreases sharply with age. This suggests international mobility decisions are mostly determined early in a career (Gaulé 2014). Women are even less likely to return (NSF 2017; Gaulé 2014).

Studies that focus on the microeconomic determinants of migration suggest that income may not be the most important determinant of deciding to return for highly skilled individuals. Gibson and McKenzie (2009) conducted a comprehensive survey of individuals who graduated high school between 1976 and 2004 and who were the highest achieving students in three Pacific countries at different levels of development: Tonga, Papua New Guinea, and New Zealand. The probability of migrating is very high for this population, and so is the probability of return migration. They find that the decision to migrate is most strongly associated with preference variables - such as risk aversion, patience, and subjects studied in secondary school-and not strongly linked with economic variables such as income or labor market conditions. The decision to return is also most strongly associated with preferences, with family and lifestyle reasons stronger predictors of return than the extent of the income gains from migrating.

Finally, the decision to return is also dependent in large measure on regulatory hurdles placed on the path to family reunification, permanent residence, and citizenship. As discussed in Chapter 2, several OECD countries already have points-based immigration systems that favor exceptionally skilled individuals. These policies, aimed at protecting job opportunities for native workers by limiting physical migration, may have the unintended consequence of encouraging technology-enabled fragmentation and outsourcing of professional services (Mattoo and Mishra 2009). 
Perhaps the truly momentous change brought by the 4IR is the spatial unfixing of work, which effectively allows the migration of work without the migration of the worker (Hamel 2009). We tend to think of this practice as outsourcing, subcontracting, or simply trade. Instead, we should consider it virtual migration - and an alternative form of labor supply - for at least three reasons (Aneesh 2006). First, outsourcing companies rarely specialize in tradable products, and, if they do, tradable products tend to be a small fraction of sales: their product is skilled work. For example, companies in the Philippines that supply medical claim processing services to insurance providers in the US are mainly supplying health professional work; or companies in India that offer development and management of digital platforms are essentially supplying professional IT work. Second, unlike other regular imports, there are no tariff or non-tariff barriers to online labor flows, and no mechanisms to monitor the massive volumes of information flowing across national borders every minute of every day. Finally, the tasks that tend to be outsourced are relatively standardized and relatively less dependent on local culture, language, and experience. So there is no difference between a given task performed onsite by a physical migrant and the same task performed offsite by a virtual migrant.

The traditional BPO model - in which operations and responsibilities are contracted to a third-party service provider - was aided by the spread of digital connectivity in the early 1990s and made it possible for destinations like India and the Philippines to capture large amounts of outsourced work. Today, as ever more people in low-income countries connect to the internet, a different type of outsourcing has emerged: digital labor platforms that allow business processes to be outsourced to the human cloud without the mediation of formal BPO organizations (see Section 4). "In this context, workers can transcend some of the constraints of their local labor markets, and tasks such as translations, transcriptions, lead generation, marketing, and personal assistance can now all, in theory, be done by workers from anywhere for clients based anywhere" (Graham et al. 2017). These online workers are therefore self-employed and are likely to hold a "portfolio" of jobs.

The advantage of virtual migration for employers is that it allows them to bypass the burdensome regulatory requirements to bring foreign workers into a country, as well as restrictions on their numbers. Before the 2008/09 global financial crisis and the subsequent eurozone crisis - when widespread unemployment brought increased public scrutiny on large companies' outsourcing practices - employers who resorted to virtual migration could also avoid the charge of "preferring immigrants to citizens" in employment and job creation, because virtual migration was conflated with trade in services. 
Governments see the potential of the gig economy and the human cloud for offering work to low-income sections of their populations. Digital Malaysia emphasizes the importance of microwork and elancing for sustaining income (MDeC 2013). The gig economy is often espoused as particularly good for caregivers, retirees, students, and others who need flexible schedules - essentially creating more demand for workers who previously might not have worked. The question remains, however: is the theory in line with reality? Evidence from the UK suggests that this can be a boon for workers in high demand; but for others who engage in the gig economy due to a lack of other options, it can make already disempowered populations increasingly vulnerable (Balaram and Stephens 2018).

The Online Labour Index (OLI), started in 2016, tracks projects posted on the five largest English-language online work platforms ${ }^{8}$ - representing $60-70 \%$ of the market by traffic - to measure how online labor platforms are used across countries over time. The Index considers only fully digital transactions (i.e., buyers and sellers of the labor or services must be matched digitally, payments must be conducted digitally, and the results of the work must be delivered digitally).

The data used to compute the OLI is collected by periodically "crawling" the list of vacancies available on each of the sample platforms. ${ }^{9}$ For each crawl, the status of each vacancy is monitored and saved: whether open, in progress, or completed. Comparing changes in status allows them to calculate the number of new and filled vacancies between two crawls. The main shortcoming of this approach is that they do not observe vacancies that were posted and completed between two crawls, which means that the OLI is likely to underestimate the total number of projects the five platforms handle. In addition, since the OLI only considers English-language platforms, the market shares of non-English-speaking countries are likely to be underrepresented in the figures.

Panel A of Figure 10.1 shows the top five employer countries. The US has by far the largest market share with $41 \%$ of posted vacancies. The UK follows with $8.5 \%$, then Australia and Canada, both at 7\%. India's fifth place with a $6 \%$ market share is not surprising considering that the country has a large IT sector that generates domestic demand for online workers, as well as a healthy international labor market intermediation services industry spanning over two decades. The "body shoppers" described by Aneesh (2006) have simply extended their domain to the human cloud: they win projects and, in turn, subcontract them to the human cloud acting as project managers. ${ }^{10}$

Panel B of Figure 10.1 breaks down the vacancies into six categories: (i) creative and multimedia; (ii) clerical and data entry; (iii) sales and marketing support (mostly related to online advertising); (iv) software development 

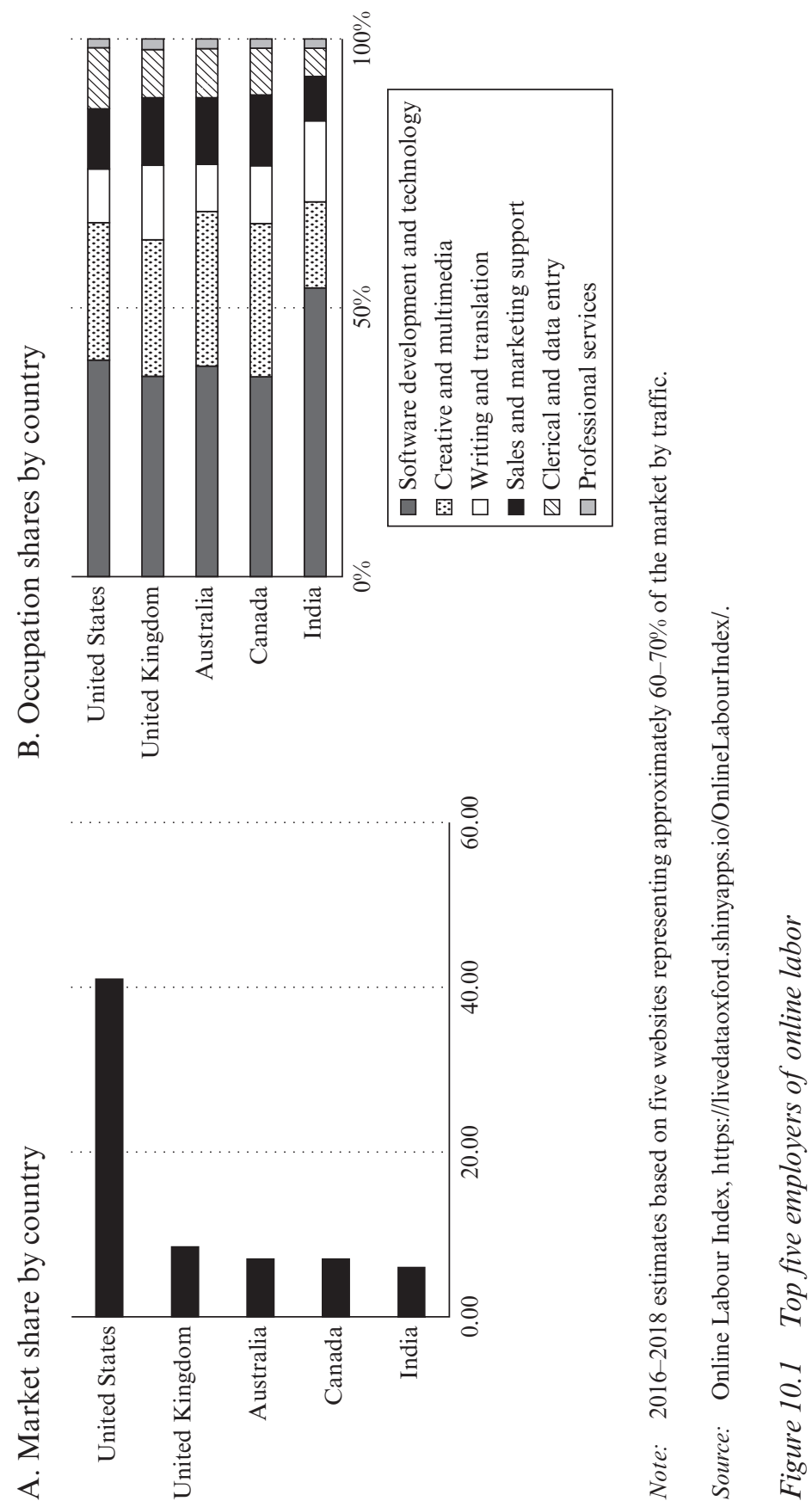
and technology; (v) writing and translation; and (vi) professional services (e.g., business consulting and legal services). Figure 10.1 shows that the distribution of posted vacancies over the six categories is relatively similar across the five countries, except for India, where a substantially higher share of vacancies is in software development and technology.

The OLI also compiles statistics on online workers for four online work platforms. ${ }^{11}$ Panel A of Figure 10.2 shows that four out of the top five worker supplier countries are in Asia. Indian workers get 26\% of posted vacancies, followed by workers in Bangladesh, Pakistan, the US, and the Philippines with $19 \%, 14 \%, 7 \%$, and $6 \%$, respectively. Overall, $71 \%$ of posted vacancies on the remaining four platforms go to workers from Asia. Panel B shows that the distribution of occupations over the six categories varies across worker countries. In India, almost half of the occupations are in software development and technology; the Philippines have the highest share of creative and multimedia occupations $(39 \%)$, followed by clerical and data entry (18\%). Bangladesh has the highest share of sales and marketing support occupations (39\%), followed by $26 \%$ in creative and multimedia occupations. The US has the highest share of writing and translation occupations, whereas workers from Pakistan seem to deal prevalently in creative and multimedia occupations $(34 \%)$, followed by software development and technology (31\%).

Because the OLI focuses on the five largest English-language online work platforms, it provides some clues on which countries have the highest demand for online labor and which countries are the largest suppliers. Interestingly, the patterns of virtual migration appear to mimic the patterns of physical migration described in Chapter 1 - virtual migrants from Asia have the highest market share and supply their labor mostly to OECD countries (with the US in first place).

Our discussion of the OLI is also useful to understand the challenges of tracking virtual migration, and how ill-suited conventional labor market statistics and economic indicators are to measuring work transacted online (McKenzie 2017). This is the main reason why the impact of virtual migration on native workers, as well as physical migrants, is not yet fully understood.

We can theorize virtual migration to affect the domestic economy the same way as physical migration (see Chapter 2). The displacement effect is the direct effect of outsourcing one or more production tasks or hiring immigrants to perform them onsite on reducing demand for native workers who perform the same tasks. The productivity effect, on the other hand, derives from the efficiency gains from outsourcing one or more tasks or hiring migrant labor onsite, which increases demand for native workers, either for the same tasks or complementary tasks. 


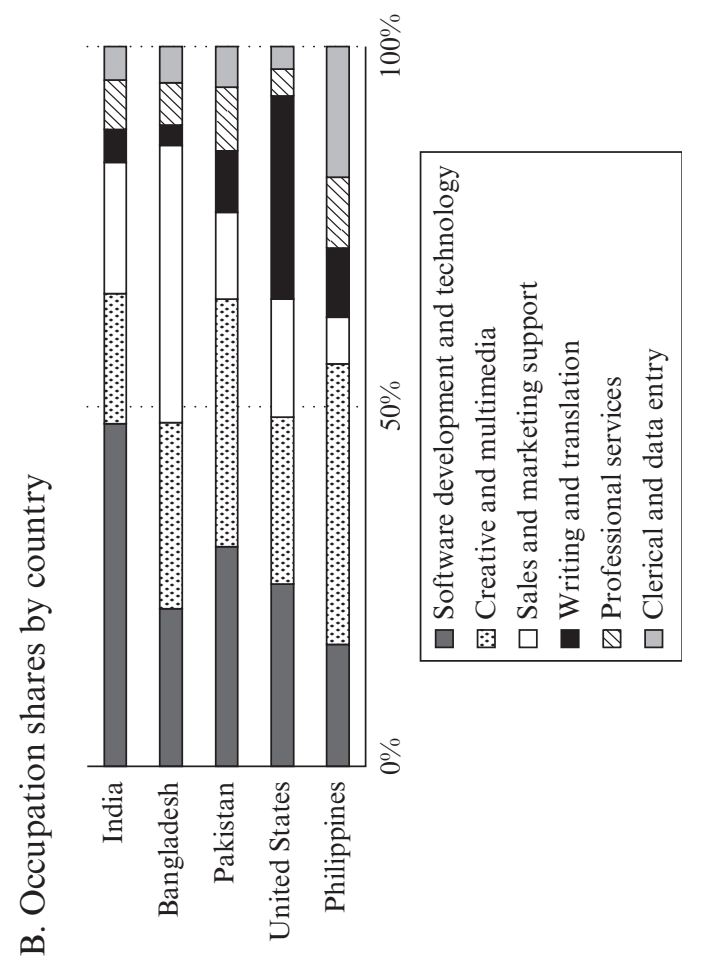

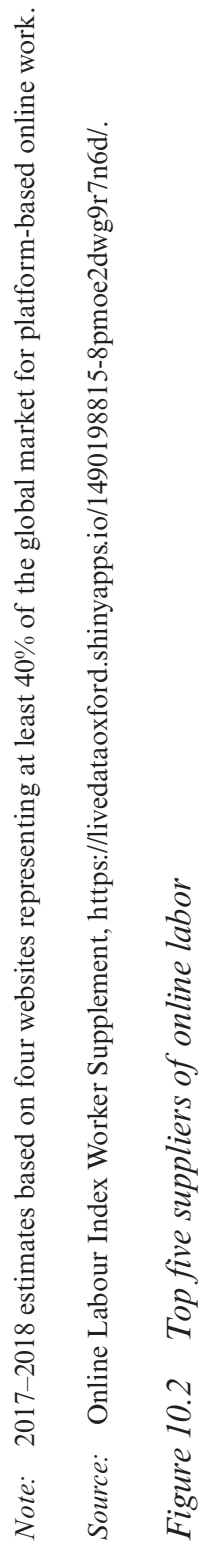


To our knowledge, no study has rigorously analyzed the impact of virtual migration on both physical migration and native employment. Ottaviano et al. (2013) come closest by using data on the US manufacturing sector - subdivided into 58 industries from 2000 to 2007-to study the simultaneous patterns of substitutability between native, immigrant, and offshore workers. However, "offshore workers" in this study are employees working abroad in foreign affiliates of US parent companies, which may only partially overlap with virtual migrants. They find that easier offshoring reduces the employment shares of both native and immigrant workers, whereas easier immigration reduces the employment share of offshore workers only-which suggests a displacement effect between offshore and migrant workers. However, when they look at employment levels, they do not find any significant effects of easier offshoring on the employment levels of either migrant or native workers, while easier immigration has a positive and mildly significant impact on natives. This suggests the presence of a strong productivity effect associated with both immigration and offshoring.

When they rank worker tasks by complexity, ${ }^{12}$ easier offshoring raises the average complexity of native tasks, whereas easier immigration has no effect. The authors suggest that it is because "immigrants are relatively specialized in low complexity tasks, natives in high complexity tasks, and offshore workers in medium complexity tasks" (Ottaviano et al. 2013, p.1926), and therefore immigrants do not compete directly with natives, whereas offshore workers generate some competition with both immigrants and natives.

Although it presents useful insights, the paper by Ottaviano et al. focuses on employees of foreign affiliates of US manufacturing firms, and therefore we do not know to what extent it captures the virtual migration phenomenon. The study is constrained by the limited data on services and the production function approach at the core of the analysis, which is much better understood within the context of manufacturing than services.

While evidence shows that physical skill flows are increasing (Chapter 1; Kerr et al. 2016), it is easy to envision that, with digitization and high-speed connectivity combined with lengthy and complicated procedures for work visas, virtual migration will continue to grow. Provisions in new "mega free trade agreements" - such as the Comprehensive and Progressive Agreement for Trans-Pacific Partnership (CPTPP) and the currently negotiated Regional Comprehensive Economic Partnership (RCEP) - will likely further support this trend. The CPTPP includes a chapter on trade in services which opens service and investment sectors to competition for members' firms without restrictions. While domestic qualification restrictions will still apply — but not to government services - it still provides a 
strong commitment to ensuring barriers to trade in services are minimized. Equally, it explicitly includes some liberalization measures to enable digital trade.

Based on the discussion so far, there is reason to believe that it is unlikely that virtual migration will replace physical migration of skilled workers in the near future, especially at the top of the skill distribution. Kremer's O-ring production function, discussed in Chapter 2, explains why the most highly skilled must work with each other and have access to specialized services and high-quality equipment to maximize productivity. Telepresence and telerobotics are not yet perfect substitutes for face-to-face interaction, and skeptics wonder if they ever will be: it is human nature, after all, to seek real connections. Equally, despite the spatial unfixing of work, talent clusters will still occur due to economies of agglomeration-achieving a critical mass of similar businesses or services in one location can create sufficient scale to attract complementary specialized inputs and service providers (McKenzie 2017).

In fact, the entire debate may be superseded by a more integrated mix of virtual and physical transitory and circular migration in the future. It is not uncommon for large contracts that could be technically fulfilled entirely through virtual migration to have a physical component. Let us consider, for example, the development of a new digital platform. Perhaps the overseas client is not aware of all available options or is not sure what the structure of the platform should be. The IT firm will send a team to the client location to determine the client's needs, assist during the test phase, and finally train users to maximize the impact of the new tool. In capacitybuilding and training activities, human interaction often helps motivate and energize the learners.

The previous sections looked at the potential impact of the 4IR on high skill flows in the region. It showed that physical migration is becoming increasingly temporary, in the form of either circular or transit migration. Furthermore, it discussed how technology is fueling the growth of virtual migration and the reasons why the potential policy implications of online work are not yet fully understood. One thing that is clear is that it is likely increasing numbers of high-skilled workers will move for work. Given the skills gap in the region (highlighted in the introduction), it is important that ASEAN countries take action to support this mobility. Section 4 moves on to consider how the 4IR can be used to reduce barriers to labor mobility, contributing to more effective and equitable regional labor markets. 


\section{HOW CAN 4IR TECHNOLOGIES SUPPORT PHYSICAL SKILLED-LABOR MOBILITY?}

The barriers to physical labor mobility are complex and multifaceted, ranging from restrictive employment regulations to access to affordable housing, to linguistic and cultural differences. Some barriers result in lower numbers of workers relocating, and some result in worker movement going unrecorded and unregulated. While certainly no panacea, 4IR technologies can help reduce some of the challenges related to asymmetric information between host countries and potential mobile skilled workers. 4IR technologies can support more informed policy making, access to tools for reskilling, and greater access to financial and social services.

First, 4IR technologies can support more informed labor market policy making. Online talent platforms such as LinkedIn or JobStreet.com provide information on what jobs are available, the skills required, career pathways, and worker retention. Partnerships between online platforms and government, combined with artificial intelligence (AI) and machine learning, could provide richer analysis of the labor market, leading to more targeted and timely labor market policies.

Talent platforms also promise to overcome the lack of information on job opportunities outside of immediate worker networks. LinkedIn is a global platform with more than 500 million users. McKinsey Global Institute (MGI 2015) estimates that online platforms may add up to $\$ 805$ billion to global GDP annually by 2025 , by reducing the time people spend looking for jobs and by enabling matches that might not have otherwise happened. Whether these platforms are in fact leading to increased physical worker mobility remains, however, a relatively unexplored area. ${ }^{13}$

Second, the 4IR will require massive reskilling and retraining, either within existing occupations or to move into new occupations. "There are few precedents in which societies have successfully retrained such large numbers of people" (MGI 2017). 4IR technologies can help meet this challenge. Online courses and massive open online courses (MOOCs) can help workers gain specific skills on their own regardless of location and at low cost. They provide training at scale, and are particularly suitable for workers in full- or part-time jobs - which make MOOCs critical to meeting the challenge of reskilling the existing workforce. For example, at Coursera, an online learning platform, half of the students are from developing countries, with about $60-70 \%$ employed but preparing for better jobs (MGI 2017). Digital learning appears to be particularly relevant for Asia, which is the second-largest e-learning market globally. Many traditional education providers are also expanding their reach through online mechanisms (for example, ChinaEdu, Korea National 
Open University, and Open University Malaysia). This is particularly true for online English-language training (Adkins 2016). ${ }^{14}$

Nevertheless, platform effectiveness is not assured. Analysis of online courses offered by Harvard and the Massachusetts Institute of Technology (MIT) found that only $30 \%$ of those intending to earn a certificate did actually do so, with the subsequent impact on their career outcomes unknown (Chuang and Ho 2016). Head (2017) warns against losing sight of the fact that technology is a tool rather than a solution.

New modalities will inevitably emerge to meet this need. For example, Gnowbe, a micro-learning app for mobile phones, promotes its ability to "activate personalized learning" through a combination of bite-sized learning modules, peer-to-peer knowledge sharing, multimedia content, and use of gamification principles. ${ }^{15}$ Greater use of digital technologies in education can also help provide more targeted and individualized teaching for students. Integration of digital technologies in teaching methods can not only increase IT skills but also support more peer-to-peer and self-directed approaches (Sarvi and Pillay 2017), which foster problem-solving and interpersonal skills, anticipated to be in increasing demand in the future.

Some blockchain applications may be particularly useful for supporting circular or transitory migration. Blockchain technology can, for example, increase the security and portability of academic credentials. Schemes are proliferating that provide instantly verifiable certificates, carried by individuals for life. In combination with digital training platforms, these would provide a secure and quick means of tracking qualifications of professionals moving within ASEAN, potentially alleviating some of the bureaucratic burden behind implementing mutual recognition agreements (MRAs).

Innovative financial service companies that use digital and 4IR technologies (FinTech) are changing how financial services are provided. For mobile workers, it can decrease the cost and increase the ease of receiving and making payments, sending remittances, and accessing other services such as loans and insurance.

In 2016, $\$ 7.8$ billion was estimated to have been remitted by ASEAN workers to ASEAN destinations (see Chapter 1). These were largely cash transfers conducted through banks or money transfer agents (e.g., Western Union). Lack of competition means transfer fees in Southeast Asia are high - an estimated 7.1\% (the UN's Sustainable Development Goals hope to reduce this globally to below 3\%). Peer-to-peer networks such as Transferwise offer much lower rates. Equally, the use of cryptocurrencies, although currently small, could become a faster and cheaper mechanism for making remittances. In the Philippines, cryptocurrency startups based on blockchain technology, such as Coins.ph and Toast, are growing fast. Coins.ph has more than 1 million users with a network of 22,000 domestic 
disbursement and collection locations (UOB 2017). Mainstream Bitcoin adoption is also surging, as Filipinos increasingly use it for remittance payments - mainly due to the inefficiency of the local banking system. The Bangko Sentral ng Pilipinas estimates that over $\$ 6$ million in remittances to the Philippines is being sent monthly in Bitcoin (Alegado 2017). Crowdsourcing for loans ${ }^{16}$ and the use of social data points ${ }^{17}$ for meeting know-your-customer requirements also offer mechanisms for people without bank accounts to receive and make payments.

Social protection services, particularly healthcare and worker compensation for foreign workers, vary across ASEAN. For instance, foreign workers in Thailand can access the public healthcare system at similar costs as citizens; but not so in Singapore (Asher and Zen 2015). Emerging economies that do not yet have well-established social protection schemes can design more appropriate and flexible systems. Flexible and transferable social protection schemes are important as they reduce barriers to labor mobility and facilitate circular or transitory migration. Campbell (2018) argues that "protected mobility' is essential when dealing with labor mobility in the 4IR.

Digital identities (eIDs) linked with blockchain technology provide a means of decreasing the cost of providing essential services and social welfare more flexibly. Blockchains offer a way to handle complex systems linked to individuals with greater data security. This could make them suitable for managing a harmonized social protection scheme transferable (or at least coordinated) within and across ASEAN.

While not without its critics, the Aadhaar ID system in India shows the potential of eID systems for providing not only social welfare payments but financial services, training, insurance, and private business services as well (e.g., mobile phone credit top-up). Estonia launched an "e-residency" scheme to allow people from overseas to tap into certain aspects of their national eID system, including greater ease in establishing online businesses. The use of eIDs for cross-border movement is growing in financial services to help decrease "onboarding" costs for new customers. ${ }^{18}$ These approaches could be extended to create mobile eIDs that both ease challenges in accessing finance and allow workers to contribute and receive payments from social welfare schemes and many other aspects of public services.

\section{FUTURE DIRECTIONS AND QUESTIONS FOR ASEAN}

While change is hard to predict, particularly in the 4IR, this chapter argues that if past trends on growth and employment in ASEAN remain relevant, 
then continued economic growth and prosperity will compensate for the displacement effects of 4IR technologies on jobs-leading to an overall growth in employment. Nevertheless, even if employment grows overall, some occupations will be hit hard, affecting worker livelihoods. This could contribute to rising national inequality, social discontent, and political backlash against migration. Combined with an existing and growing skills mismatch within the region, this adds to the urgency for ASEAN to address skills mobility as critical.

As barriers to communication continue to decline across the world, and the 4IR requires greater worker flexibility, two key trends emerge. First is a clear pattern of return and circular migration, as well as transit migration, for skilled workers. Return migration is consistent with successful migrants leaving once they have reached their savings or human capital accumulation targets; transit migration stems from skilled workers' willingness to move from country to country for opportunities to advance their skills. The second key trend is that the workers of the 4IR are more likely to be self-employed and hold a portfolio of jobs. Combined, these two trends mean that work visa policies and procedures must be reformed. The process of obtaining a visa cannot take longer than the stay itself; and if workers are self-employed and working for multiple employers, their visas cannot be tied to a single employer or make it difficult to transfer to a different employer. Currently, ASEAN citizens find it easier to emigrate outside the region; and it may well be that workers who are not ASEAN citizens find it easier than ASEAN citizens to obtain a work visa in the region. ASEAN needs a preferential work-based immigration system for its member citizens.

Another issue associated with increasingly temporary migration and increasingly self-employed workers is eligibility for social security benefits - especially as it pertains to self-employed individuals - which varies widely across countries. Furthermore, benefit portability is also problematic, as migrant workers may lose access in their home countries before qualifying for benefits in their host countries.

There is tremendous potential for regional coordination, using 4IR technologies such as blockchains. ASEAN could support student circulation and create an evidence base to support MRAs for professionals by providing portable academic credentials and effective credit swapping mechanisms across ASEAN universities. Similarly, a regional eID could provide a basis for more expedient work visa procedures, as well as costefficient and secure access to social protection and services to mobile and transitory skilled workers.

While research shows that skilled worker migration is increasingly temporary and transitory, it also shows that highly skilled individuals, 
while perhaps more mobile at the beginning of their career, are less likely to return. Indeed, the highly specialized nature of their skills, which makes them deployable only in a few settings, combined with the high recognition that they receive in their host countries, explains this divergence.

That is why we believe skills mobility remains strategically important to support ASEAN growth and inclusiveness. Skilled workers-and the highly skilled in particular - need an enabling environment to make the most efficient use of their skills. While technologies such as telerobotics and telepresence are increasingly sophisticated, they do not yet perfectly substitute face-to-face interaction. Equally, the economies of agglomeration will continue to provide benefits to talent clustering. Therefore, governments must support talent clusters through place-based strategies centered on university research centers, science parks, and other enablers of business growth (Berriman and Hawksworth 2017). This place-based approach also involves extending the latest digital infrastructure beyond major urban centers to overcome the digital divide and increase opportunities for rural populations. Finally, place-based policies also involve creating a better regional infrastructure to reduce the costs of the flow of services, goods, and people (Duranton and Venables 2018).

Enabled by the spatial unfixing of work, virtual migration is also on the rise, and it has evolved from the traditional BPO model, in which operations and responsibilities are contracted to a third-party service provider, to digital platforms that allow tasks to be subcontracted directly to the human cloud. Our analysis based on the OLI, albeit limited to the largest English-language online work platforms, suggests that the patterns of virtual migration mimic the patterns of physical migration-virtual migrants from Asia hold the highest market share and supply labor mostly to OECD countries (with the US highest).

The impact of online work and associated virtual migration on physical migration and native workers is not yet fully understood. Initial research in the US suggests there may be some displacement effects between offshore workers, skilled migrants, and native workers, but that productivity gains compensate in terms of employment growth. Further research is required to better understand this interaction, not only in ASEAN but in the rest of the world as well. This is particularly pertinent in the context of ongoing trade in services liberalization under mega trade agreements like the CPTPP and the RCEP.

While physical migration is heavily regulated and taxed, virtual migration is commonly considered outsourcing, subcontracting, or trade in services, and largely unregulated and undetected. Existing tax laws were developed in a world of physical goods and in-person services. But for online labor, even the location of the worker is difficult to determine - it 
could be the IP address of the worker, the location of the server of the digital platform that connects the worker to the employer, or the location where the virtual migrant supplies labor (e.g., a Filipino worker works for a US customer from the Philippines through the mediation of a digital platform with servers located in Ireland).

The stated purpose of heavy barriers to physical skill flows is to protect employment opportunities for local workers; but in practice they are likely to tilt the scale in favor of virtual migration whenever it is technologically and culturally feasible. Therefore, we argue that barriers to physical migration should be reduced, making physical and virtual migration subject to the same labor regime as much as possible. This would increase oversight of standards, increase the taxation base, and help protect worker rights.

To understand and quantify the impact of 4IR technologies on jobs in ASEAN, as well as the interaction of physical and virtual skill flows with native workers, ASEAN must both strengthen its capacity in collecting labor market statistics and harmonize those statistics across the region. That would include developing an ASEAN-wide platform to track the stock and flow of skilled workers (including vocational workers), and using surveys harmonized with the OECD's Programme for the International Assessment of Adult Competencies (PIAAC) to enable analysis of the task content of occupations and how it evolves.

However, the new economy of the 4IR is largely undetected by conventional labor market statistics and economic indicators. AI and machine learning have "the potential to use a wealth of data, frequently crowdsourced or publicly available, to look for data patterns and correlations that [...] could help illuminate successful approaches to anticipating migration flows, harnessing skills, and better understanding the power of remittances" (Eldridge et al. 2017).

Equally outside conventional labor market statistics-although representing the majority of intra-ASEAN migrants - are the undocumented workers in construction, agriculture and fisheries, and domestic services. The fact that they work the so-called " $3 \mathrm{D}$ " jobs - dirty, dangerous, and demeaning - does not necessarily mean they are low skilled. The lack of recognition of their qualifications, combined with a lack of opportunities in their home countries, may force many into occupations they are overqualified for, contributing to brain waste (see Chapter 2). Furthermore, as megatrends like rapid urbanization and population aging transform ASEAN's labor force, workers like caregivers and bricklayers will be more and more essential to the region.

A more inclusive MRA that includes vocational occupations - combined with a preferential work-based immigration system for ASEAN citizens and mobile eIDs tied to a host of services - would go far toward address- 
ing the concerns of host countries, while at the same time protecting the rights of migrant workers and harnessing their full potential. As migrants increasingly use social media to acquire information on opportunities and tap into support networks, AI can be a game-changer in detecting triggers and patterns of undocumented migration to devise adequate policy responses.

ASEAN wants to be at the forefront of change and embrace new technologies. It has also demonstrated its commitment to promoting skilled-labor mobility within the AEC. It is time for ASEAN members to bring this vision to life and bring the 4IR future inexorably closer.

\section{NOTES}

* We thank Rana Hasan and Jayant Menon for peer reviewing the chapter, and Mia Kim Veloso for excellent research assistance.

1. A sewbot is a fully automated garment-producing machine.

2. This is the so-called "Factory Asia" model.

3. Technological advances could trigger "reshoring"- the reintroduction of previously offshored manufacturing to a country - if the offshore location loses its cost advantage. Reshoring (or onshoring) is the reverse process of offshoring, where manufacturing is moved to another country where operating costs are lower.

4. The ASEAN members included in this analysis are Indonesia, Malaysia, the Philippines, Thailand, and Viet Nam; the other economies are Bangladesh, India, the People's Republic of China (PRC), the Republic of Korea, Mongolia, Sri Lanka, and Taipei,China.

5. Thailand's lower number is surprising considering that the country not only had a very low unemployment rate, but was also experiencing labor shortages in key economic sectors. Furthermore, Thailand's aging population and rising education levels also means that fewer people are available for routine manual occupations.

6. Digitization is the process of converting information into a digital (i.e., computerreadable) format in which the information is organized into bits.

7. "Circular migration refers to repeated migration experiences between an origin and destination involving more than one migration and return" (Hugo 2013). It is "based on a continuing, long-term, and fluid relationship among countries that occupy what is now increasingly recognized as a single economic space" (Agunias and Newland 2007).

8. The five platforms are Freelancer, Guru, Mturk, PeoplePerHour, and Upwork.

9. A web crawler, or simply crawler, is a program that systematically browses the internet, typically for the purpose of web indexing. A crawler can be instructed to archive a list of websites, in which case it copies and saves the information in repositories that can be viewed, read, and navigated as they were on the live web but preserved as "snapshots."

10. "Body shoppers" are firms that specialize in finding talent on demand for overseas clients. The recruited worker, for example a software developer, is deployed at the overseas client's premises on a temporary basis, but the entire time they are employed by the local body shopper, not the overseas client. This is different from headhunters, who find workers that match the profile requested by the customer for a fee.

11. The four platforms are Fiverr, Freelancer, Guru, and PeoplePerHour.

12. The authors "consider the complexity of a task to be increasing in the intensity of use of communication and cognitive skills and decreasing in the manual content of the task" (Ottaviano et al. 2013, p. 1926).

13. Most studies on the impact of online job platforms look at career mobility and use the data to review movement of flows, but the impact of the platform itself is hard to ascertain. 
14. The highest growth rate (in terms of the value of sales) for digital English-language learning globally is Myanmar, with a 60\% growth rate predicted between 2015 and 2020 . The Lao PDR, Cambodia, Malaysia, and Indonesia also have projected growth rates well above $30 \%$.

15. This refers to learning reminders, notifications by short message service (SMS), and e-mail and trigger-based e-mails and reminders.

16. Consider CrowdCredit, Crowdo, CreditEase.

17. Social data points include information not typically part of a credit record, i.e., connections on Facebook, mobile phone behavioral data.

18. Meaning the verification process when opening a new account.

\section{REFERENCES}

Adkins, Sam S. (2016). The 2015-2020 Asia-Pacific Digital English Language Learning Market. Ambient Insight.

African Development Bank Group, Asian Development Bank, European Bank for Reconstruction and Development, Inter-American Development Bank (2018). The Future of Work: Regional Perspectives. Washington, DC: AfDB, EBRD, IDB.

Agunias, Dovelyin Rannveig, and Kathleen Newland (2007). Circular Migration and Development: Trends, Policy Routes, and Ways Forward. Policy Brief. Migration Policy Institute (MPI).

Alegado, Siegfrid (2017). Philippines Eyes Rules for Coin Offerings as Bitcoin Use Surges. Bloomberg. https://www.bloomberg.com/news/articles/2017-12-04/ philippines-eyes-rules-for-coin-offerings-as-bitcoin-use-surges.

Aneesh, A. (2006). Virtual Migration: The Programming of Globalization. Durham, NC: Duke University Press.

Arntz, Melanie and Terry Gregory, and Ulrich Zierahn (2016). The Risk of Automation for Jobs in OECD Countries: A Comparative Analysis. OECD Social, Employment and Migration Working Papers, No. 189. Paris: OECD Publishing.

Artuc, Erhan and Çağlar Özden (2018). Transit Migration: All Roads Lead to America. The Economic Journal 128(612): F306-34.

ASEAN (2016). Master Plan on ASEAN Connectivity 2025. Jakarta: ASEAN Secretariat.

Asher, Mukul G. and Fauziah Zen (2015). Social Protection in ASEAN: Challenges and Initiatives for Post-2015 Vision. Discussion Paper No. 6. Jakarta: Economic Research Institute for ASEAN and East Asia (ERIA).

Asian Development Bank (2017a). Asian Economic Integration Report 2017: The Era of Financial Interconnectedness. Manila: Asian Development Bank.

Asian Development Bank (2017b). Reinventing Mutual Recognition Arrangements: Lessons from International Experiences and Insights for the ASEAN Region. Manila: Asian Development Bank.

Asian Development Bank (2018). How Technology Affects Jobs. Asian Development Outlook 2018. Manila: Asian Development Bank. April 2018.

Autor, David H. and David Dorn (2013). The Growth of Low-Skill Service Jobs and the Polarization of the US Labor Market. American Economic Review 103(5): 1553-97.

Autor, David H. and Frank Levy, and Richard J. Murnane (2003). The Skill Content of Recent Technological Change: An Empirical Exploration. Quarterly Journal of Economics 118(4): 1279-333. 
Baldwin, Richard (2016). The Great Convergence: Information Technology and the New Globalization. Cambridge, MA: Belknap Press of Harvard University Press.

Balaram, Brhmie and Fabian Wallace-Stephens (2018). Thriving, Striving or Just about Surviving? Seven Portraits of Economic Security and Modern Work in the $U K$. Future Work Centre and RSA (Royal Society for the encouragement of Arts, Manufactures and Commerce) Report.

Berriman, Richard and John Hawksworth (2017). Will Robots Steal Our Jobs? The Potential Impact of Automation on the UK and Other Major Economies. UK Economic Outlook, March 2017, PricewaterhouseCoopers LLP UK. https:// www.pwc.co.uk/economic-services/ukeo/pwcukeo-section-4-automation-march2017-v2.pdf.

Bertulfo, Donald Jay and Elisabetta Gentile, and Gaaitzen De Vries (2019). The Employment Effects of Technological Innovation and Participation in Global Value Chains: Evidence from Asia. ADB Economics Working paper No. 572, Asian Development Bank (ADB).

Bijwaard, Govert E. and Jackline Wahba (2014). Do High-Income or Low-Income Immigrants Leave Faster? Journal of Development Economics 108: 54-68.

Campbell, Duncan (2018). Work and Social Protection in the 4th Industrial Revolution. Working paper.

Chang, Jae-Hee and Phu Huynh (2016). ASEAN in Transformation: The Future of Jobs at Risk of Automation. Geneva: International Labour Organization.

Chuang, Isaac and Andrew Ho (2016). HavardX and MITx: Four Years of Open Online Courses. Fall 2012-Summer 2016. https://ssrn.com/abstract=2889436; http://dx.doi.org/10.2139/ssrn.2889436.

Duranton, Gilles and Anthony J. Venables (2018). Place-based Policies for Development. Working Paper No. 24562. National Bureau of Economic Research (NBER).

Eldridge, Richard and Kahlid Koser, and Mariah Levin and Sanjiv Rai (2017). What Does the Fourth Industrial Revolution Mean for Migration? World Economic Forum Global Agenda, https://www.weforum.org/agenda/2017/06/what-does-the -fourth-industrial-revolution-mean-for-migration/.

Frey, Carl Benedikt and Michael A. Osborne (2017). The Future of Employment: How Susceptible Are Jobs to Computerisation? Technological Forecasting and Social Change 114: 254-80.

Gaulé, Patrick (2014). Who Comes Back and When? Return Migration Decisions of Academic Scientists. Economics Letters 124: 461-4.

Gibson, John and David McKenzie (2009). The Microeconomic Determinants of Emigration and Return Migration of the Best and Brightest: Evidence from the Pacific. Discussion Paper No. 3926, Forschungsinstitut zur Zukunft der Arbeit (IZA).

Global Commission on International Migration (2005). Migration in an Interconnected World: New Directions for Action. Geneva: GCIM.

Graham, Mark, Isis Hjorth, and Vili Lehdonvirta (2017). Digital Labour and Development: Impacts of Global Digital Labour Platforms and the Gig Economy on Worker Livelihoods. European Review of Labour and Research 23(2): 135-62.

Hamel, Jean-Yves (2009). Information and Communication Technologies and Migration. Human Development Research Paper No. 39, United Nations Development Programme (UNDP)

Head, Karen, J. (2017). Disrupt This! MOOCS and the Promises of Technology. Hanover, NH: University Press of New England. 
Hugo, Graeme (2013). What We Know about Circular Migration and Enhanced Mobility. Policy Brief No. 7. Migration Policy Institute (MPI).

International Labour Organization (2011). ILO Four-Country Study on Public Attitudes to Migrant Workers. Bangkok: ILO Regional Office for Asia and the Pacific.

International Labour Organization and Asian Development Bank (2014). ASEAN Community 2015: Managing Integration for Better Jobs and Shared Prosperity. Bangkok: ILO and ADB.

Kerr, Sari Pekkala, William Kerr, Çağlar Özden, and Christopher Parsons (2016). Global Talent Flows. Working Paper No. 22715. National Bureau of Economic Research (NBER).

Kobayashi, Kiyoshi, Khairuddin Abdul Rashid, Masahiko Furuichi, and William P. Anderson (2017). Economic Integration and Regional Development: The ASEAN Economic Community. New York: Routledge.

Malaysia Digital Economy Corporation (2013). Digital Malaysia Progress Report 2012. Cyberjaya: Malaysia Digital Economy Corporation.

Mattoo, Aaditya and Deepak Mishra (2009). Foreign Professionals in the United States: Regulatory Impediments to Trade. Journal of International Economic Law 12(2): 435-56.

McKenzie, Fiona (2017). The Fourth Industrial Revolution and International Migration. Working Paper No. 5. Lowy Institute for International Policy.

McKinsey Global Institute (2015). A Labor Market that Works: Connecting Talent with Opportunity in the Digital Age. McKinsey \& Company Executive Summary.

McKinsey Global Institute (2017). Jobs Lost, Jobs Gained: Workforce Transitions in a Time of Automation. New York: McKinsey \& Company.

National Science Foundation (2017). Doctorate Recipients from US Universities: 2015. Special Report NSF 17-306. Arlington, VA: National Science Foundation, National Center for Science and Engineering Statistics.

Organisation for Economic Co-operation and Development (2018). International Migration Outlook 2018. Paris: OECD Publishing.

Ottaviano, Gianmarco I.P., Giovanni Peri, and Greg C. Wright (2013). Immigration, Offshoring, and American Jobs. American Economic Review 103(5): 1925-59.

Sarvi, Jouko and Hitendra Pillay (2017). Innovations in Knowledge and Learning: Postsecondary Education Reform to Support Employment and Inclusive Growth. Manila: ADB.

Schwab, Klaus (2016). The Fourth Industrial Revolution. Geneva: World Economic Forum.

Stewart, Ian and Debapratim De, and Alex Cole (2015). Technology and People: The Great Job-Creating Machine. London: Deloitte LLP.

Susskind, Richard and Daniel Susskind (2015). The Future of the Professions: How Technology Will Transform the Work of Human Experts. Oxford: Oxford University Press.

Tunon, Max and Nilim Baruah (2012). Public Attitudes towards Migrant Workers in Asia. Migration and Development 1(1): 149-62.

United Overseas Bank (2017). State of FinTech in ASEAN. Singapore: United Overseas Bank Limited.

World Economic Forum and Asian Development Bank (2017). ASEAN 4.0: What Does the Fourth Industrial Revolution Mean for Regional Economic Integration? Geneva: WEF and ADB. 